\title{
Research on the Relationship between Currency Circulation Speed and Inflation
}

\author{
Yuemei Sun \\ Zhengzhou University of Industrial Technology, Henan, Zhengzhou, 451150
}

Keywords: currency circulation; circulation speed; inflation

\begin{abstract}
This paper mainly expounds the trend of the velocity of currency circulation from the perspective of the relationship between the velocity of currency circulation and inflation, discusses the relationship between the velocity of currency circulation and inflation, analyzes it from different angles, and provides a reference for the study of the relationship between the speed of currency circulation and inflation.
\end{abstract}

\section{Introduction}

Every country is striving for the steady growth of the economy, but according to the actual situation, it is difficult for social and economic development to continue to develop in a balanced state and the economic growth will always be presented in a cyclical way. In the situation, since 2004, China has once again entered the stage of inflation and has shown a steady rise. Especially in 2007, China's consumer price index rose to $4.8 \%$. In order to prevent excessive inflation, the state issued corresponding Policies and means to tighten monetary policy, thus effectively mitigating economic fluctuations. From another perspective, the speed of money circulation can also play a role in influencing monetary policy. At the same time, the velocity of money circulation can reflect the growth rate and supply of money. Therefore, we must study the relevance of speed of money circulation and the inflation.

\section{Background analysis of the relationship between the velocity of money circulation and inflation}

Because of the seriousness and great destructiveness of inflation, it has become a global problem, which will not only affect the economy of a country but also affect the stability of people's lives and society. Therefore, inflation is widely concerned by society. However, in order to ensure the stable development of the social economy, we must do economic measures such as suppressing inflation and stabilizing prices. China has experienced two serious inflations since its opening, one from 1988 to 1989 and the other from 1993 to 1995 . Therefore, it is necessary to analyze the causes of this situation based on the previous two inflations to provide guarantees for future economic development and prevent recurrence of inflation. According to the actual situation, domestic research on inflation and currency circulation speed is mainly based on theoretical analysis and quantitative analysis is rarely carried out mainly because the relevant theoretical knowledge is scarce. Developed countries mainly rely on perfect market economic conditions as the basic theory. Implementing inflation research, many model formulas and knowledge theory are difficult to apply to China. To analyze domestic inflation, we must proceed from the traditional concept, analyze according to the development characteristics of the new period, and obtain effective data. Focus on the relationship between inflation and the speed of money circulation, and then implement further predictions and analysis.

\section{Analysis of the trend of currency circulation speed}

When describing the quantity of money, it can be implemented by the following formula, namely $\mathrm{MV}=\mathrm{PY}$, which mainly relates the currency circulation speed, the money stock, and the income level. By deriving, the following formula is obtained, that is, $d P / P+d Y / Y=d V / V+d M / M$, if you use 
lowercase letters, you can get the following formula, ie $m+v=+y$, where the output rate is expressed by $\mathrm{y}$, the inflation rate is expressed, the currency circulation speed is expressed by $\mathrm{v}$, and the currency growth rate is used. $\mathrm{M}$ indicates that according to the formula, it can be understood that there is a certain correlation between the rate of change of the velocity of money circulation, the rate of change of money supply, the rate of change of total national production and the rate of inflation. According to relevant data, the change in the speed of China's currency circulation shows cyclical changes and the cycle shows a trend of change. The economic growth rate is affected by the speed of money circulation and the rate of increase and decrease of the velocity of money. When the national economy shows growth, the velocity of money flows. It will show a downward trend. If the national economy shows a low tide, the velocity of money circulation will show a downward trend. Economic growth will lead to changes in the demand for money, which will have a certain correlation between the economic growth cycle and the speed of money circulation. Fast, people's income will grow, and at the same time lead to increased inflation expectations, making people's desire for consumption increase, further speeding up the flow of money.

\section{Analysis of the relationship between the velocity of money circulation and inflation}

\subsection{Correlation analysis of inflationary currency circulation speed}

First, the effect of inflation on the speed of money circulation. In the process of inflation, the speed of money circulation does not decrease with the rise of money supply but accelerates with the increase of the speed of money circulation. If the money supply leads to inflation If it happens all the time, the speed of money circulation will lead to serious inflation. It can be seen that inflation is a monetary phenomenon. From a deeper perspective, inflation is a question of the speed of money circulation. From the perspective of monetarism, changes in the inflation rate will lead to a corresponding change in the speed of money circulation, that is, inflation is attached to enterprises and households in an alternative way of taxation, thereby accelerating the circulation of money among different social and economic entities by reducing the currency balance and increase the share of non-monetary assets to minimize the losses caused by inflation. At this time, the price of the commodity has risen and the situation continues until the decrease in the demand for the money balance is equal to the decrease in the actual money stock. The comprehensive analysis shows that the inflation rate has risen and the currency circulation speed will gradually increase.

\subsection{The relationship between the speed of money circulation and the pressure of invisible accomplices}

Generally, inflationary pressure will be reflected in the difference between the total supply and the total demand. It mainly consists of two parts, one is inflationary pressure and the other is shortage and object rise, that is, the sum of shortage and price increase is equal to inflationary pressure. Once the price gap and inflation pressure are equal, it means that the social economy is in a balanced state and the reasons for the total supply and total demand gap include the following aspects: insufficient effective supply, excessive money supply and cost promotion, but not blindly. From the perspective of the commodity market, it is also necessary to analyze from the perspective of the entire macro-economy, that is, when part or all of the inflation gap is transformed into a shortage gap, it represents that the social economy is in a non-equilibrium state, although the price has not changed for a while, the trend of rising prices and the pressure will accumulate. In the normal process of social and economic development, many of the currencies in the inflationary environment are affected by administrative rations, non-free price systems and macro shortages. After a shortage, they are in a state of savings even though these savings are not in the state of savings and will cause price changes, but some non-price changes will occur. In addition, when inflation expectations occur, it will lead to an increase in the price of some raw materials, which will lead to the phenomenon of early snapping, which will cause price fluctuations, but it is difficult to display the demand level. Therefore, in order to obtain effective aggregate demand indicators, Inflation is used for analysis. Although the velocity of money circulation is presented as a constant, 
it still shows some fluctuations according to the actual situation, but it will show a stable trend. In view of the speed of China's currency circulation, fluctuations occur within a certain period of time and the causes of fluctuations are diversified, mainly including macroeconomic changes, institutional changes and economic cycle changes. These fluctuations will affect inflation at the same time affecting the macro economy. If the speed of money circulation exceeds the equilibrium state within a certain period of time, the social economy will effectively act, investment and consumption will be further liberalized, prices will rise and inflation will be effectively reduced. The pressure brought about, on the contrary, if the velocity of money is lower than the equilibrium in a certain period of time, the social economy will be depressed, investment demand and consumer demand will decrease, prices will be stable, and eventually inflationary pressure will increase.

Concluding remarks: In summary, after two inflations experienced in China in the 20th century, the entire social economy has been seriously affected. Therefore, we must obtain effective experience from it, conduct in-depth research from different angles and implement the trend toward currency circulation. At the time of the study, the relevant data showed that the speed of money circulation was reduced. The main factors were the rapid development of marketization and the further improvement of the degree of economic monetization. From the traditional mode of money payment, the development of the value-added function towards the asset appreciation function and the new era environment The circulation of electronic money has further played a role in currency substitution. According to the actual situation analysis, when testing inflation, we should analyze the relationship between the speed of money circulation and inflation. In the process of inflation, the speed of money circulation does not decrease with the increase of money supply. It is accelerating with the increase of the speed of money circulation. If the money supply causes inflation to occur all the time, the speed of money circulation will lead to serious inflation. Therefore, we must attach great importance to the various effects brought about by the speed of money circulation. The actual operating state is analyzed according to the economy to adjust the basic currency plays an important role in the macroeconomic regulation and control of the society so we need to coordinate the relationship between the speed of money circulation and inflation and provide effective protection for social and economic development.

\section{References}

[1] Jun Li. Research on the Relationship between Money Supply, Currency Circulation Speed and Inflation_-Based on Comparison between the United States, Japan, Britain and China[J]. Southern Finance,2011(2):4-8

[2] Juan Mao. Does the virtual economy currency circulation speed have a monetary policy indicator function? —Based on the empirical research of China's stock market from 2006 to 2010[J]. Economic Perspectives (mid-term issue), 2011(4):178-180

[3] Dan Wu. Analysis of the Importance of Generalized Currency Circulation Speed to Stabilize Prices_-An Empirical Analysis Based on Chinese Data[J]. Journal of Shanxi Finance and Taxation College, 2016(3): 64-68

[4] Xinghua Zhang, Biao Luo. The Blocking Mechanism in the Transmission of Monetary Policy_ A Study on the Decline of Inflation Rate under Loose Monetary Policy[J]. Financial Forum,2016(7):22-39 